\title{
Maximum Rate of Pressure Development and Maximal Relaxation Rate of Respiratory Muscles in Patients with Cystic Fibrosis
}

\author{
Theodore G Dassios MD, Stavros Doudounakis MD, and Gabriel Dimitriou MD PhD
}

\begin{abstract}
BACKGROUND: Respiratory muscle function in patients with cystic fibrosis (CF) has been studied by measurement of maximal inspiratory pressure $\left(\mathbf{P}_{\text {Imax }}\right)$, maximal expiratory pressure $\left(\mathbf{P}_{\text {Emax }}\right)$, and the pressure-time index of the respiratory muscles $\left(\mathrm{PTI}_{\mathrm{mus}}\right)$. The maximum rate of pressure development (MRPD) during $\mathbf{P}_{\text {Imax }}\left(M R P D-P_{I \max }\right)$, MRPD during $\mathbf{P}_{\text {Emax }}\left(\right.$ MRPD- $\mathbf{P}_{\text {Emax }}$ ), maximal relaxation rate $(M R R)$ during $P_{\text {Imax }}\left(M R R-P_{\text {Imax }}\right)$, and $M R R$ during $P_{E \operatorname{Eax}}\left(M R R-P_{E \max }\right)$ have not been studied in CF. Our aim was to study MRPD and MRR and investigate their possible application as accessory indices of respiratory muscle function in patients with CF. METHODS: FEV , FVC, and maximal expiratory flow between $25 \%$ and $75 \%$ of vital capacity, body mass index

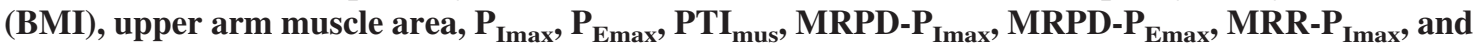
MRR-P $P_{\text {Emax }}$ were assessed in $123 \mathrm{CF}$ patients and in a control group of 123 healthy subjects matched for age and sex. RESULTS: MRR-P $P_{\text {Emax }}$ was significantly increased and MRPD- $P_{E \operatorname{Eax}}$ was significantly decreased in the CF patients, compared to the healthy controls. In the CF patients MRR-P $_{\text {Imax }}$ was significantly related to PTI $_{\text {mus }}(P=.02)$, FEV $_{1}(P=.03)$, FVC $(P=.001)$, BMI $(P<.001)$, and upper arm muscle area $(P<.001)$. In the CF patients, MRPD-P Imax and MRPD$P_{\text {Emax }}$ were significantly related to upper arm muscle area $(P<.001)$, BMI $(P<.001$ and $P=.01$, respectively), $P_{I \max }(P<.001)$, and $P_{E \max }(P<.001)$. CONCLUSIONS: The $C F$ patients exhibited increased MRR and decreased MRPD during maximal respiratory effort, compared to controls.

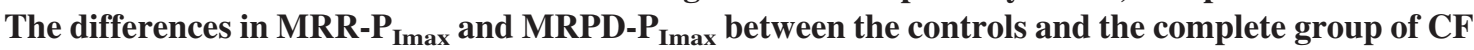
patients were not significant. MRPD and MRR were significantly related to nutritional and pulmonary function impairment in CF patients. MRPD strongly correlated to maximal respiratory muscle pressures, and MRR strongly correlated to PTI $_{\text {mus }}$ in patients with $C F$. These findings suggest that $\mathrm{CF}$ patients are at increased risk of respiratory muscle fatigue. Regular determination of MRPD and MRR may be clinically useful in CF patients and help to initiate inspiratory muscle training and noninvasive ventilation. Key words: cystic fibrosis; respiratory muscles; spirometry; nutritional deficiency. [Respir Care 2013;58(3):474-481. (C) 2013 Daedalus Enterprises]
\end{abstract}

\section{Introduction}

Respiratory muscle function in cystic fibrosis (CF) has been studied utilizing a wide variety of methods and in-

\footnotetext{
Dr Dassios is affiliated with the Neonatal Intensive Care Unit, Addenbrooke's Hospital, Cambridge University Hospitals, National Health Service Foundation Trust, Cambridge, United Kingdom. Dr Doudounakis is affiliated with the Department of Cystic Fibrosis, Aghia Sophia Children's Hospital, Athens, Greece. Dr Dimitriou is affiliated with the Department of Paediatrics, University of Patras Medical School, Patras, Greece.
}

The authors have disclosed no conflicts of interest. dices. Maximal inspiratory pressure $\left(\mathrm{P}_{\operatorname{Imax}}\right)$ and maximal expiratory pressure $\left(\mathrm{P}_{\mathrm{Emax}}\right)$ have been used to describe properties of respiratory muscle strength, ${ }^{1,2}$ while the noninvasive pressure-time index of the respiratory muscles $\left(\mathrm{PTI}_{\text {mus }}\right)$ has also been applied to describe respiratory muscle function. ${ }^{3,4}$ Chronic obstruction and hyperinflation,

\footnotetext{
Correspondence: Theodore G Dassios MD, Neonatal Intensive Care Unit, Addenbrooke's Hospital, Cambridge University Hospitals National Health Service Foundation Trust, Hills Road, Cambridge, CB2 OSW, United Kingdom. E-mail: tdassios@upatras.gr.
}

DOI: $10.4187 /$ respcare. 01930 
manifested by affected pulmonary function indices, might contribute to impaired respiratory muscle function in patients with $\mathrm{CF}, 5,6$ while chronic malnourishment might be associated with decreased respiratory muscle strength., ${ }^{4,7}$ Other factors that impact respiratory muscle function in CF include chronic inflammation, lung parenchymal damage, and the direct effects of hypoxemia and hypercapnia on muscle function. ${ }^{8}$

The maximum rate of pressure development (MRPD) during the initial linear incline of the $\mathrm{P}_{\operatorname{Imax}}$ curve has been used to assess respiratory muscle function. ${ }^{9}$ MRPD has been studied in healthy adult individuals as a means to assess the effect of inspiratory muscle training on inspiratory muscle function. ${ }^{10}$ Furthermore, decreases in relaxation rate of skeletal muscles upon cessation of contraction are generally recognized to describe muscle fatigue as a result of reduced calcium uptake. ${ }^{11}$ Slowing in the rate of decline of inspiratory pressure, as demonstrated by decrease of the maximum relaxation rate (MRR), is an accepted and reliable index of respiratory muscle fatigue. ${ }^{11}$ Inspiratory muscle MRR can be assessed noninvasively by measuring the MRR at the nose during a sniff nasal inspiratory pressure maneuver. ${ }^{11,12}$

The increased work load faced by the respiratory muscles due to airway obstruction, hyperinflation, and suboptimal nutrition places the respiratory muscles in patients with $\mathrm{CF}$ in mechanical disadvantage and predisposes $\mathrm{CF}$ patients to respiratory muscle fatigue and respiratory failure. ${ }^{13}$ Indices that describe respiratory muscle function have been found to be affected in CF. ${ }^{3,4}$ To our knowledge, MRPD and MRR have not been previously studied in patients with CF.

Our hypothesis was that MRR and MRPD would be decreased in patients with $\mathrm{CF}$, compared to healthy controls, during maximal static respiratory pressure maneuvers. The objective of this study was thus to compare MRR and MRPD during maximal static respiratory pressure maneuvers in CF patients and healthy individuals. Secondary aims were to assess possible relation of these indices to well established indices of respiratory muscle function such as maximal respiratory pressures and $\mathrm{PTI}_{\text {mus }}$, as well as to establish possible contributions of nutrition and pulmonary function impairment to MRR and MRPD in patients with $\mathrm{CF}$.

\section{Methods}

\section{Subjects}

CF patients attending the Department of Cystic Fibrosis of Aghia Sophia Children's Hospital in Athens, Greece, for regular evaluation were investigated. This department follows some patients into adulthood, and subjects were included irrespective of age. The control group consisted

\section{QUICK LOOK}

\section{Current knowledge}

In patients with cystic fibrosis, pathophysiologic disturbances in pulmonary function and chronic malnourishment lead to respiratory muscle dysfunction, which is commonly quantified by measurement of the maximal inspiratory and expiratory pressures.

\section{What this paper contributes to our knowledge}

The maximal rate of pressure development and maximal relaxation rate during measurement of maximal inspiratory pressure in subjects with cystic fibrosis were significantly different from normal subjects. Larger differences in the maximal rate of pressure development and maximal relaxation rate were strongly associated with nutritional and pulmonary dysfunction. These measurements may play a role in monitoring cystic fibrosis patients.

of healthy children and young adults with no history of respiratory disease matched for age and sex and enrolled at the pediatric department of the University Hospital of Patras, Greece. CF diagnosis was made by abnormal sweat test results and confirmed with expanded mutation analysis. ${ }^{14}$ Patients with exacerbation during the past month, on steroid therapy, or with coexisting pulmonary pathology were excluded from the study. Children younger than 6 years old were excluded from the study, as they were unable to perform the necessary pulmonary function and respiratory muscle function maneuvers. Standard chest physical therapy was undertaken by all CF patients. The study protocol was approved by the hospital's ethics committee. Caregivers, or subjects when appropriate, provided informed written consent prior to the study, while consent was also sought and obtained from older children and adolescents.

\section{Measurements}

\section{Maximal Relaxation Rate and Maximum Rate of Pressure Development}

MRR and MRPD were assessed during maximal inspiratory and maximal expiratory efforts against an occluded airway, using a handheld respiratory pressure meter (MicroRPM, CareFusion, San Diego, California). MRR was calculated as the first derivative of pressure with respect to time over the first half of the relaxation curve ${ }^{11}$ and expressed as a percentage of the pressure fall in $10 \mathrm{~ms}^{12}$ MRPD was assessed and defined as the positive peak of 
the pressure derivative as a function of time during the initial incline of the maximal respiratory pressure curve. ${ }^{10}$

\section{Measurement of Respiratory Pressures}

Flow was measured with a pneumotachograph (Mercury F100L, GM Instruments, Kilwinning, Scotland) connected to a differential pressure transducer (DP45, range $\pm 3.5 \mathrm{~cm} \mathrm{H}_{2} \mathrm{O}$, Validyne Engineering, Northridge, California). Airway pressure was recorded from a side port on the pneumotachograph, connected to a differential pressure transducer (DP45, range $\pm 225 \mathrm{~cm} \mathrm{H}_{2} \mathrm{O}$, Validyne Engineering, Northridge, California). From the differential pressure transducers the signals were amplified (CD280, Validyne Engineering, Northridge, California), recorded, and displayed with data analysis software (Labview, National Instruments, Austin, Texas) with analog-to-digital sampling at $100 \mathrm{~Hz}$ (16-bit NI PCI-6036E, National Instruments, Austin, Texas). $\mathrm{P}_{\text {Imax }}, \mathrm{P}_{\text {Emax }}$, airway-occlusion pressure at $0.1 \mathrm{~s}$ after the start of inspiration $\left(\mathrm{P}_{0.1}\right)$, breathing frequency, tidal volume $\left(\mathrm{V}_{\mathrm{T}}\right)$, minute ventilation, inspiratory time $\left(\mathrm{T}_{\mathrm{I}}\right)$, total time of respiration $\left(\mathrm{T}_{\text {tot }}\right)$, and $\mathrm{T}_{\mathrm{I}} / \mathrm{T}_{\text {tot }}$ were measured. $\mathrm{P}_{0.1}$ was calculated as the airway pressure $0.1 \mathrm{~s}$ after an occlusion while the subject was quietly breathing. Five airway occlusions were performed, and the average value for $\mathrm{P}_{0.1}$ value was calculated. $\mathrm{P}_{\text {Imax }}$ was measured at residual volume against an occluded airway upon a maximal inspiratory effort. ${ }^{15} \mathrm{P}_{\text {Emax }}$ was measured at total lung capacity against an occluded airway upon a maximal expiratory effort. ${ }^{15}$ Both $\mathrm{P}_{\text {Imax }}$ and $\mathrm{P}_{\text {Emax }}$ were measured on the basis of 5 maximal reproducible respiratory efforts, and the maximum achieved value was recorded. A small needle leak in the respiratory circuit allowed for avoidance of glottic closure and falsely elevated pressure recordings. ${ }^{11} \mathrm{~A}$ unidirectional valve (total dead space $8 \mathrm{~mL}$ ) attached to the rubber mouthpiece was used to perform the occlusions. Care was taken to eliminate any leak around the mouthpiece. Only $\mathrm{P}_{\text {Imax }}$ and $\mathrm{P}_{\text {Emax }}$ maneuvers with plateau pressure for at least $1 \mathrm{~s}$ were accepted for subsequent analysis. ${ }^{11}$

\section{Calculation of Pressure-Time Index of the Respiratory Muscles}

$\mathrm{PTI}_{\text {mus }}$ was calculated as:

$$
\mathrm{PTI}_{\text {mus }}=\left(\mathrm{P}_{\text {Imean }} / \mathrm{P}_{\text {Imax }}\right) \times\left(\mathrm{T}_{\mathrm{I}} / \mathrm{T}_{\text {tot }}\right)
$$

where $\mathrm{P}_{\text {Imean }}$ is for the average airway pressure during inspiration, derived from the formula $\mathrm{P}_{\text {Imean }}=5 \times \mathrm{P}_{0.1} \times \mathrm{T}_{\mathrm{I}}$, $\mathrm{P}_{\text {Imax }}$ is the maximum inspiratory airway pressure, $T_{I}$ is the inspiration time, and $T_{\text {tot }}$ is the total time for each breath, calculated from the airway flow signal., 416,17

\section{Lung Function Tests}

$\mathrm{FEV}_{1}$, maximal expiratory flow between $25 \%$ and $75 \%$ of vital capacity $\left(\mathrm{MEF}_{25-75 \%}\right)$, and FVC were measured (MasterScreen, Jaeger/CareFusion, San Diego, California). The pulmonary function tests were performed according to European Respiratory Society guidelines ${ }^{18}$ and are expressed as percentage of normal values (\% predicted). ${ }^{19}$ The limits utilized for the staging of pulmonary function tests were based on the pulmonary function score developed by Cropp et al. ${ }^{5}$

\section{Nutritional Parameters}

Body mass index (BMI) was calculated as the body weight of the individual in kilograms, divided by the square of his height in meters. ${ }^{20}$ The BMI z-score method was used for subjects ages 6-19 years, while for individuals older than 20 years the BMI method was used..$^{21}$ Mid-arm muscle circumference (MAMC) was measured to the nearest centimeter, midway between the tip of the acromion and the olecranon process, with the right hand hanging relaxed. ${ }^{22}$ Triceps skinfold thickness (TST) was measured to the nearest millimeter, halfway over the triceps muscle (Harpenden Skinfold Caliper, Baty International, West Sussex, United Kingdom) with the skinfold parallel to the longitudinal axis of the arm. ${ }^{22}$ From these indices upper arm muscle area (UAMA) was calculated. ${ }^{23}$

\section{Statistics}

Data were assessed for normality with the application of the Kolmogorov-Smirnoff and Shapiro-Wilk tests. Differences between groups were assessed for significance with the Mann-Whitney rank sum test. Linear regression analysis was used to examine the relation of MRPD and MRR to $\mathrm{PTI}_{\text {mus }}, \mathrm{P}_{\text {Imax }}$ and $\mathrm{P}_{\mathrm{Emax}}$ and the relation of MRPD and MRR to $\mathrm{FEV}_{1}, \mathrm{MEF}_{25-75 \%}$, FVC, UAMA, BMI, and BMI Z-score. Variables without normal distribution were logarithmically transformed. Statistical analysis was performed using statistics software (SPSS 17.0, SPSS, Chicago, Illinois).

\section{Results}

Between November 2009 and September 2010, 123 subjects were included in the study. The control group consisted of 123 healthy individuals matched as possible for age and sex. Ages ranged from 6 to 34 years.

Nutritional parameters such as weight, height, and BMI did not achieve significant differences between the $\mathrm{CF}$ and the control groups, while BMI z-score was significantly lower in the $\mathrm{CF}$ group, compared to the control group 


\section{Maximum Rate of Pressure Development and Relaxation Rate of Respiratory Muscles}

Table 1. Anthropometric, Nutrition, Spirometric, and Respiratory Muscle Function Data

\begin{tabular}{|c|c|c|c|}
\hline & $\begin{array}{l}\text { Healthy Subjects } \\
\quad(n=123)\end{array}$ & $\begin{array}{l}\text { Cystic Fibrosis } \\
\quad(n=123)\end{array}$ & $P$ \\
\hline Male, no. (\%) & $72(58.5)$ & $66(53.7)$ & $.59 *$ \\
\hline Age, y & $13(10-17)$ & $14(10-17)$ & $.42 \dagger$ \\
\hline Height, cm & $158(146-168)$ & $158(140-168)$ & $.26 \dagger$ \\
\hline Weight, kg & $51(40-62)$ & $49(36-59)$ & $.11 \dagger$ \\
\hline Body mass index, $\mathrm{z}$-score & $0.53(-0.30$ to 1.21$)(n=98)$ & $0.22(-0.42$ to 0.87$)(n=103)$ & $.04 \dagger$ \\
\hline Body mass index, $\mathrm{kg} / \mathrm{m}^{2}$ & $22.1(20.0-24.6)(n=25)$ & $21.3(2.0-23.8)(n=20)$ & $.35 \dagger$ \\
\hline Mid-arm muscle circumference, $\mathrm{cm}$ & $24.0(22.0-27.0)$ & $22.0(19.6-25.0)$ & $<.001 \dagger$ \\
\hline Triceps skinfold thickness, mm & $14(11-18)$ & $12(8-15)$ & $<.001 \dagger$ \\
\hline Upper arm muscle area, $\mathrm{mm}^{2}$ & $3,145(2,595-3,828)$ & $2,624(1,985-3,490)$ & $<.001 \dagger$ \\
\hline FVC, $\%$ predicted & NA & $103.3(84.3-118.6)$ & NA \\
\hline $\mathrm{FEV}_{1}, \%$ predicted & NA & $100.3(74.0-117.4)$ & NA \\
\hline $\mathrm{MEF}_{25-75 \%}, \%$ predicted & NA & $71.6(41.3-103.6)$ & NA \\
\hline Breathing frequency, breaths/min & $19(15-23)$ & $18(15-22)$ & $.17 \dagger$ \\
\hline $\mathrm{V}_{\mathrm{T}}, \mathrm{L}$ & $0.590(0.420-0.720)$ & $0.510(0.365-0.680)$ & $.01 \dagger$ \\
\hline $\mathrm{V}_{\mathrm{T}}, \mathrm{mL} / \mathrm{kg}$ body weight & $11.2(8.4-16.0)$ & $10.5(8.4-14.9)$ & $.55 \dagger$ \\
\hline Minute ventilation, $\mathrm{L} / \mathrm{min}$ & $10.95(8.50-13.69)$ & $9.15(7.03-11.63)$ & $<.001 \dagger$ \\
\hline $\mathrm{V}_{\mathrm{T}} / \mathrm{T}_{\mathrm{I}}, \mathrm{L} / \mathrm{s}$ & $0.395(0.327-0.526)$ & $0.342(0.270-0.440)$ & $<.001 \dagger$ \\
\hline $\mathrm{T}_{\mathrm{I}}, \mathrm{s}$ & $1.37(1.17-1.70)$ & $1.46(1.17-1.78)$ & $.24 \dagger$ \\
\hline $\mathrm{T}_{\text {tot }}, \mathrm{s}$ & $3.16(2.56-3.88)$ & $3.32(2.70-4.05)$ & $.18 \dagger$ \\
\hline $\mathrm{T}_{\mathrm{I}} / \mathrm{T}_{\text {tot }}$ & $0.44(0.42-0.46)$ & $0.44(0.42-0.47)$ & $.86 \dagger$ \\
\hline $\mathrm{P}_{0.1}, \mathrm{~cm} \mathrm{H}_{2} \mathrm{O}$ & $2.54(1.75-3.48)$ & $2.69(1.92-3.83)$ & $.31 \dagger$ \\
\hline $\mathrm{P}_{\text {Imean }}, \mathrm{cm} \mathrm{H}_{2} \mathrm{O}$ & $17.4(12.6-24.0)$ & $19.1(13.0-27.1)$ & $.15 \dagger$ \\
\hline $\mathrm{P}_{\text {Imax }}, \mathrm{cm} \mathrm{H}_{2} \mathrm{O}$ & $84(66-102)$ & $76(57-97)$ & $.046 \dagger$ \\
\hline $\mathrm{P}_{\text {Imean }} / \mathrm{P}_{\text {Imax }}$ & $0.217(0.158-0.314)$ & $0.259(0.179-0.367)$ & $.01 \dagger$ \\
\hline $\mathrm{PTI}_{\text {mus }}$ & $0.092(0.069-0.137)$ & $0.115(0.078-0.165)$ & $.01 \dagger$ \\
\hline $\mathrm{P}_{\text {Emax }}, \mathrm{cm} \mathrm{H}_{2} \mathrm{O}$ & $84(65-104)$ & $72(50-96)$ & $.002 \dagger$ \\
\hline MRR-P Imax & $2(1-3)$ & $2(2-3)$ & $.35 \dagger$ \\
\hline MRPD-P Imax & $267(199-376)$ & $255(178-373)$ & $.35 \dagger$ \\
\hline MRR-P $P_{\text {max }}$ & $2(1-3)$ & $2(1-4)$ & $.02 \dagger$ \\
\hline MRPD-P $\mathrm{Emax}$ & $354(239-530)$ & $281(178-419)$ & $.001 \dagger$ \\
\hline 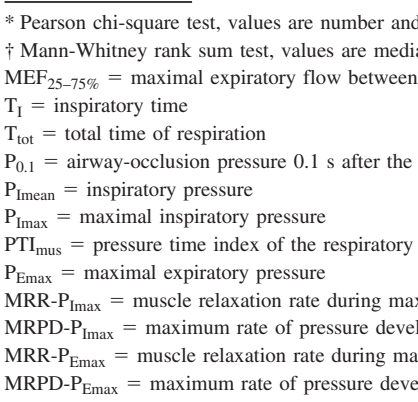 & $\begin{array}{l}\text { pressure maneuver } \\
\text { aximal inspiratory pressure maneuver } \\
\text { pressure maneuver } \\
\text { aximal expiratory pressure maneuver }\end{array}$ & & \\
\hline
\end{tabular}

(Table 1). MAMC, TST, and UAMA were found to achieve significantly lower values in the CF subjects, compared to the healthy controls (see Table 1).

Breathing cycle components in the CF subjects and controls are presented in Table 1. Breathing frequency, $\mathrm{T}_{\mathrm{I}}$, $\mathrm{T}_{\text {tot }}$, and $\mathrm{T}_{\mathrm{I}} / \mathrm{T}_{\text {tot }}$ were not significantly different between the subjects and controls, while $\mathrm{V}_{\mathrm{T}}$, minute ventilation and $\mathrm{V}_{\mathrm{T}} / \mathrm{T}_{\mathrm{I}}$ were all significantly decreased in the CF group, compared to the controls. $\mathrm{V}_{\mathrm{T}} / \mathrm{kg}$ was not significantly dif- ferent between the CF subjects and the control group (see Table 1).

Respiratory muscle strength parameters such as $\mathrm{P}_{\text {Imax }}$ and $\mathrm{P}_{\text {Emax }}$ were significantly decreased in the CF group, compared to the control group, while $\mathrm{P}_{\text {Imean }} / \mathrm{P}_{\text {Imax }}$ and $\mathrm{PTI}_{\text {mus }}$ were significantly prolonged in CF subjects compared to healthy controls (see Table 1). $\mathrm{P}_{0.1}$ and $\mathrm{P}_{\text {Imean }}$ failed to achieve significant difference between the subject and control groups. 


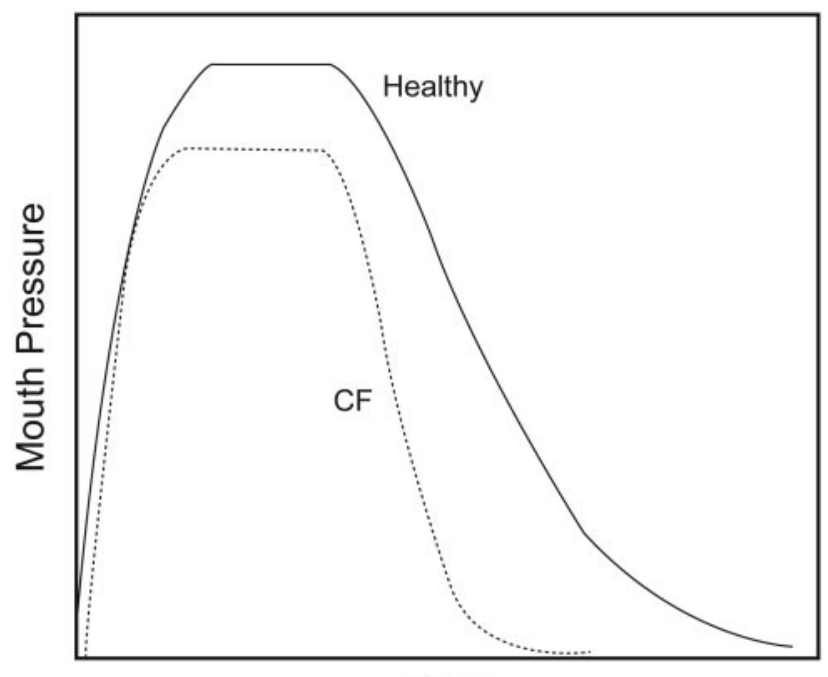

Time

Fig. 1. Typical pressure-time curves during forced expiration against an occluded airway in cystic fibrosis (CF) patients and healthy controls. The increased maximal relaxation rate during the maximal expiratory pressure in CF, compared to healthy controls, is represented by the steeper pressure fall during the first half of the relaxation curve.

MRPD- $P_{\text {Emax }}$ was significantly decreased and MRR$\mathrm{P}_{\text {Emax }}$ was significantly increased in the CF group, compared to the control group (Fig. 1), while MRPD-P Imax and MRR-P Imax were not significantly different (see Table 1).

Dividing the CF cohort according to pulmonary function values produces the data presented in Table 2. CF subjects with decreased $\mathrm{FEV}_{1}$ values, compared to $\mathrm{CF}$ subjects with normal or less affected $\mathrm{FEV}_{1}$, are found to achieve significantly lower MRPD- $\mathrm{P}_{\text {Emax }}$ but not significantly different MRPD- $\mathrm{P}_{\text {Imax }}$, while MRR was not significantly different in these groups, regardless of whether the maneuvers were performed during maximal inspiration or expiration. The CF subjects with affected FVC had significantly increased MRR-P $\mathrm{P}_{\operatorname{Imax}}$ (Fig. 2) but not significantly different MRR-P $\mathrm{Emax}_{\text {max }}$, MRPD-P $\mathrm{P}_{\text {Imax }}$, or MRPD$\mathrm{P}_{\text {Emax }}$ compared to the CF subjects with normal or less affected FVC. The CF subjects with affected $\mathrm{MEF}_{25-75 \%}$ failed to exhibit any significant difference in MRR or MRPD upon maximal inspiration or maximal expiration, compared to the CF subjects with normal or less affected $\mathrm{MEF}_{25-75 \%}$.

In the $\mathrm{CF}$ group there was a significant negative relation between MRR-P $\mathrm{Imax}_{\text {max }}$ and weight $(\mathrm{r}=-0.46, P<.001)$, height $(\mathrm{r}=-0.44, P<.001)$, and BMI $(\mathrm{r}=-0.37$, $P<.001$ ), but not between MRR-P ${ }_{\text {Imax }}$ and BMI z-score. MRR-P Imax $_{\text {in }}$ CF subjects was significantly negatively related to MAMC ( $\mathrm{r}=-0.43, P<.001)$, TST $(\mathrm{r}=-0.23$, $P=.01)$, and UAMA $(\mathrm{r}=-0.33, P<.001)$, as well as to $\mathrm{FEV}_{1}(\mathrm{r}=-0.20, P=.03)$ and $\mathrm{FVC}(\mathrm{r}=-0.30$, $P=.001)$. There was a significant positive relation in the
CF subjects between MRR-P $\mathrm{P}_{\text {Imax }}$ and $\mathrm{PTI}_{\text {mus }}(\mathrm{r}=0.22$, $P=.02$ ), but no significant relation was demonstrated between MRR- $\mathrm{P}_{\text {Imax }}$ and $\mathrm{P}_{\text {Imax }}$ or $\mathrm{P}_{\text {Emax }}$.

MRPD- $\mathrm{P}_{\text {Imax }}$ in CF subjects was significantly positively related to weight $(\mathrm{r}=0.47, P<.001)$, height $(\mathrm{r}=0.41$, $P<.001)$, BMI $(\mathrm{r}=0.36, P<.001)$, MAMC $(\mathrm{r}=0.38$, $P<.001)$, and UAMA ( $\mathrm{r}=0.47, P<.001)$, but not to BMI z-score or TST. No significant relation was established in the CF subjects between MRPD-P Imax and FEV ${ }_{1}$, $\mathrm{MEF}_{25-75 \%}$, or FVC. There was a significant positive relation in the CF subjects between MRPD- $\mathrm{P}_{\text {Imax }}$ and $\mathrm{P}_{\text {Imax }}$ ( $\mathrm{r}=0.64, P<.001)$, and between MRPD- $\mathrm{P}_{\mathrm{Imax}}$ and $\mathrm{P}_{\mathrm{Emax}}$ ( $\mathrm{r}=0.43, P<.001)$, but not between MRPD-P $\mathrm{I}_{\max }$ and PTI $_{\text {mus }}$.

MRR-P $\mathrm{P}_{\text {Emax }}$ in the CF subjects was significantly negatively related to height $(\mathrm{r}=-0.22, P=.013)$, but not to weight, BMI, BMI z-score, MAMC, TST, UAMA, FEV ${ }_{1}$, $\mathrm{MEF}_{25-75 \%}, \mathrm{FVC}, \mathrm{P}_{\text {Imax }}, \mathrm{P}_{\text {Emax }}$, or PTI $\mathrm{Pus}_{\text {. }}$.

MRPD- $\mathrm{P}_{\text {Emax }}$ in the CF subjects was significantly positively related to height $(\mathrm{r}=0.36, P<.001)$, weight $(\mathrm{r}=0.41, P<.001)$, BMI $(\mathrm{r}=0.30, P=.01)$, MAMC $(\mathrm{r}=0.34, P<.001)$, UAMA $(\mathrm{r}=0.45, P<.001), \mathrm{P}_{\mathrm{Imax}}$ $(\mathrm{r}=0.65, P<.001)$, and $\mathrm{P}_{\mathrm{Emax}}(\mathrm{r}=0.52, P<.001)$ but not to TST, $\mathrm{FEV}_{1}, \mathrm{MEF}_{25-75 \%}$, FVC, and BMI z-score. MRPD- $P_{E \max }$ was also found to achieve a significant negative relation with $\mathrm{PTI}_{\text {mus }}(\mathrm{r}=-0.24, P=.007)$.

\section{Discussion}

This study demonstrated that MRR is increased and MRPD is decreased during maximal expiration in CF subjects, compared to healthy controls. In the CF subjects, MRR-P Imax $_{\text {max }}$, MRPD- $\mathrm{P}_{\text {Imax }}$, and MRPD- $\mathrm{P}_{\text {Emax }}$ were significantly related to UAMA and anthropometric indices such as weight, height, and BMI. Only MRR-P $\mathrm{P}_{\max }$ was significantly related to $\mathrm{FEV}_{1}$ and $\mathrm{FVC}$ in $\mathrm{CF}$ subjects. In the CF group, MRR- $\mathrm{P}_{\text {Imax }}$ and MRPD- $\mathrm{P}_{\text {Emax }}$ were significantly related to PTI $_{\text {mus }}$, while MRPD-P Imax $_{\text {and }}$ aRPD$\mathrm{P}_{\text {Emax }}$ were both significantly related to $\mathrm{P}_{\mathrm{Imax}}$ and $\mathrm{P}_{\mathrm{Emax}}$.

Our results suggest that respiratory muscle function is compromised in patients with $\mathrm{CF}$ and that these patients are at increased risk of respiratory muscle fatigue. Factors that determine MRR and MRPD in CF patients might include airway obstruction and poor nutrition. These findings highlight the role of airway disease and undernutrition in the pathogenesis of respiratory muscle fatigue and respiratory failure in patients with $\mathrm{CF}$.

Analysis of respiratory muscle function by means of MRPD has been studied in the scope of investigating the effect that inspiratory muscle training has on respiratory muscle function. ${ }^{9}$ Inspiratory muscle training in healthy males produced a significant rise in MRPD. ${ }^{24}{ }^{10}$ Our study reports lower MRPD values, compared to the previously published studies, ${ }^{10,24}$ which, given the differences in the 


\section{Maximum Rate of Pressure Development and Relaxation Rate of Respiratory Muscles}

Table 2. MRR, MRPD, and Pulmonary Function Indices in the Cystic Fibrosis Patients

\begin{tabular}{|c|c|c|c|c|c|c|c|c|c|}
\hline & \multicolumn{3}{|c|}{$\mathrm{FEV}_{1}$ Category } & \multicolumn{3}{|c|}{$\mathrm{MEF}_{25-75 \%}$ Category } & \multicolumn{3}{|c|}{ FVC Category } \\
\hline & $\begin{array}{c}<80 \% \\
\text { Predicted } \\
(n=36)\end{array}$ & $\begin{array}{c}>80 \% \\
\text { Predicted } \\
(n=82)\end{array}$ & $P^{*}$ & $\begin{array}{c}<52 \% \\
\text { Predicted } \\
(n=41)\end{array}$ & $\begin{array}{c}>52 \% \\
\text { Predicted } \\
(n=75)\end{array}$ & $P^{*}$ & $\begin{array}{c}<73 \% \\
\text { Predicted } \\
(n=19)\end{array}$ & $\begin{array}{c}>73 \% \\
\text { Predicted } \\
(n=99)\end{array}$ & $P^{*}$ \\
\hline MRR-P ${ }_{\text {Imax }}$ & $3(2-4)$ & $2(2-3)$ & .12 & $2(1-4)$ & $2(2-3)$ & .83 & $3(2-5)$ & $2(2-3)$ & .02 \\
\hline MRPD-P ${ }_{\text {Imax }}$ & $215(147-394)$ & $267(202-387)$ & .16 & $216(163-394)$ & $264(197-395)$ & .32 & $212(159-403)$ & $261(194-384)$ & .31 \\
\hline MRR-P $\mathrm{P}_{\text {max }}$ & $3(2-4)$ & $2(1-3)$ & .31 & $3(1-4)$ & $2(2-3)$ & .84 & $3(2-4)$ & $2(1-3)$ & .42 \\
\hline MRPD-P ${ }_{\text {Emax }}$ & $222(154-348)$ & 329 (194-446) & .043 & $226(159-433)$ & 329 (202-438) & .11 & $187(135-539)$ & $310(193-424)$ & .16 \\
\hline
\end{tabular}

* Mann-Whitney rank sum test.

$\mathrm{MEF}_{25-75 \%}=$ maximal expiratory flow between $25 \%$ and $75 \%$ of vital capacity

MRR-P $\mathrm{P}_{\mathrm{Imx}}=$ muscle relaxation rate during maximal inspiratory pressure maneuver

MRPD-P $_{\text {Imax }}=$ maximum rate of pressure development during maximal inspiratory pressure maneuve

MRR- $\mathrm{P}_{\mathrm{Emax}}=$ muscle relaxation rate during maximal expiratory pressure maneuver

MRPD- $\mathrm{P}_{\mathrm{Emax}}=$ maximum rate of pressure development during maximal expiratory pressure maneuver

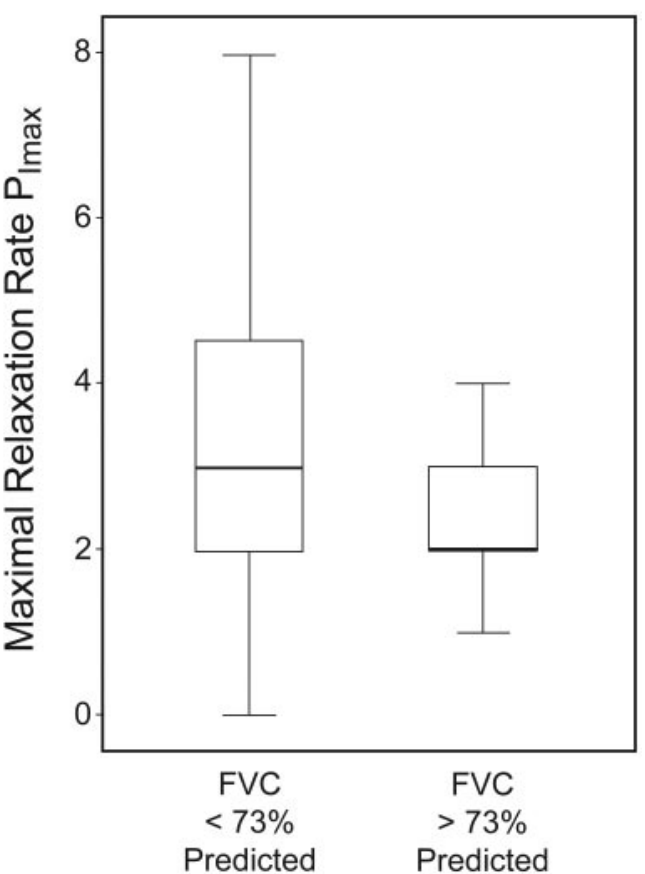

Fig. 2. Maximal relaxation rate during the maximal expiratory pressure maneuver (MRR-P $\mathrm{IImax}_{\text {) }}$ ) in CF patients with FVC $<73 \%$ of predicted, and in CF patients with FVC $>73 \%$ of predicted. The horizontal lines represent the 5th, 25th, 50th, 75th, and 95th percentiles of the MRR-P Imax values.

age groups, is not a surprising finding. No data exist in the literature reporting MRPD values in the pediatric population or in CF patients, precluding the possibility of comparing our data to data derived from a similar population. MRPD-P ${ }_{\text {Emax }}$ was decreased in CF patients with decreased $\mathrm{FEV}_{1}$, as compared to $\mathrm{CF}$ patients with normal or less affected $\mathrm{FEV}_{1}$, to a level that just reached statistical significance. MRPD- $\mathrm{P}_{\text {Emax }}$ and MRPD- $\mathrm{P}_{\text {Imax }}$ were both significantly related to maximal respiratory pressures in $\mathrm{CF}$ patients, while MRPD- $\mathrm{P}_{\text {Emax }}$ and MRPD-P $\mathrm{P}_{\text {Imax }}$ were also found to achieve a significant relation to weight, height, BMI, MAMC, and UAMA underlying the well reported relation of malnutrition and respiratory muscle compromise in CF. ${ }^{2,4}$ Furthermore, the significant negative relation of MRPD-P $\mathrm{Emax}_{\text {mo }} \mathrm{PTI}_{\text {mus }}$ in CF patients might reflect the balance disruption between the respiratory load and neuromuscular competence that has been described in $\mathrm{CF}$ patients. ${ }^{13}$

MRR can be invasively measured with 2 balloon catheters measuring esophageal and gastric pressures and thus obtaining the transdiaphragmatic pressure and the corresponding MRR, which is calculated as the first derivative of pressure over time during the first half of the relaxation curve. ${ }^{11}$ Transdiaphragmatic MRR has been shown to slow post induced fatigue in healthy young men. ${ }^{25}$ Mulvey et al ${ }^{26}$ studied sniff MRR at esophageal and transdiaphragmatic pressures and concluded that MRR became faster at sniff peak pressures that exceeded $10 \%$ of an individual's maximal pressure. Comparison of MRR following short, sharp inspiratory efforts against an occluded airway (mouth) or unoccluded nostril concluded that the unoccluded nostril method produced more consistent and quantitatively greater MRR changes, as compared to the occluded mouth method. ${ }^{27}$ Kyroussis et al introduced the concept of measuring MRR noninvasively at the level of the nostrils during unoccluded sniff of increasing intensity reaching maximal effort, as nasal MRR was found to reflect esophageal MRR over a wide range of sniff pressures. ${ }^{12}$

Our study examined MRR after a maximal static inspiratory and expiratory effort against an occluded airway.

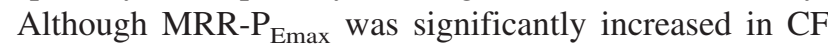
patients, compared to healthy controls, this index in $\mathrm{CF}$ patients was not related to pulmonary function indices or nutritional indices, with the exception of height. Furthermore, abdominal muscle recruitment is known to occur during active forced expiration, and air-flow obstruction is associated with prolonged expiration, further diminishing 


\section{Maximum Rate of Pressure Development and Relaxation Rate of Respiratory Muscles}

the possible utility of this index in describing respiratory muscle function. MRR- $\mathrm{P}_{\text {Emax }}$ is a global index that does not differentiate the relative contributions of the respiratory and abdominal muscles in forced expiration. The fact that MRR-P $\mathrm{Emax}_{\text {mas }}$ significantly increased in the $\mathrm{CF}$ subjects, compared to controls, might represent a selective training effect that $\mathrm{CF}$ lung disease imposes on the abdominal muscles, as it is well known that airway obstruction promotes active expiration and abdominal muscle recruitment. MRR-P $\mathrm{P}_{\text {Imax }}$ was significantly related to $\mathrm{FEV}_{1}$, FVC, as well as height, weight, BMI, MAMC, TST, and UAMA in CF. Additionally, the CF subjects with decreased FVC were found to attain slower MRR values, as compared to the CF subjects with normal or less affected FVC.

Affected pulmonary function and poor nutrition have previously been associated with respiratory muscle function compromise in subjects with CF in studies that utilized different indices to assess respiratory muscle function, such as maximal pressures ${ }^{2}$ and PTI $_{\text {mus }}{ }^{3,4}$ Furthermore, decreased $\mathrm{FEV}_{1}$ has been associated with increased elastic load and work of breathing in CF patients. ${ }^{28}$ The association of respiratory muscle function to nutritional indices, and namely indices that describe muscular state, such as MAMC and UAMA, has been highlighted in previous studies, ${ }^{4}$ while respiratory muscle strength has been found to correlate significantly to limb muscle strength. ${ }^{1,29} \mathrm{Al}-$ though MRR attains significantly different values between patients and controls, as well as between CF patients of different spirometric severity, this finding appears blunted by the limited number of integer values that this index attains.

MRR and MRPD during $\mathrm{P}_{\text {Imax }}$ were not significantly different between $\mathrm{CF}$ and healthy controls, which might partially reflect the fact that our patient population was found as a whole not to suffer from severe airway obstruction (median $\mathrm{FEV}_{1}$ was $100.3 \%$ of predicted).

Our study reports significantly higher $\mathrm{PTI}_{\text {mus }}$ and significantly lower $\mathrm{P}_{\operatorname{Imax}}$ and $\mathrm{P}_{\text {Emax }}$ values in $\mathrm{CF}$ subjects, compared to healthy controls. This observation is in agreement with previous studies that investigated these indices in CF patients. ${ }^{1,3,4}$ Indices that describe respiratory drive, such as $\mathrm{P}_{0.1}$ and breathing frequency, were not significantly different between the CF group and the controls, probably reflecting the relatively good pulmonary condition of our CF cohort (median $\mathrm{FEV}_{1}$ was $100.3 \%$ of predicted) with the exception of $\mathrm{V}_{\mathrm{T}} / \mathrm{T}_{\mathrm{I}}$, which nevertheless is not corrected for weight. $\mathrm{V}_{\mathrm{T}} / \mathrm{kg}$ was not significantly different in the CF subjects, compared to the control group. Nutrition indices such as MAMC, TST, UAMA, and BMI z-score were significantly lower in the CF subjects, compared to the healthy controls, and this is in accordance with previously published data, ${ }^{3,4}$ while weight, height, and BMI failed to reach statistically significant difference between the 2 groups.
Evaluation of respiratory muscle function by MRPD and MRR bears the advantage that it can be easily performed at the bedside with a portable handheld device. Our findings on MRPD and MRR in subjects with CF bear potential clinical implications. Decision to initiate inspiratory muscle training of variable intensity can be decided on the basis of the values that these indices attain, reflecting different levels of severity of respiratory muscle compromise and highlighting the potential danger of respiratory muscle fatigue. MRR and MRPD can also be used to aid the decision on initiating noninvasive ventilation with a view to improve gas exchange, preserve respiratory muscle function, and prevent or treat respiratory exacerbations. ${ }^{13}$ Further research on the effect of inspiratory muscle training and aerobic exercise on MRPD and MRR, and on the association of these indices with adverse clinical outcomes, might be of particular clinical interest.

Our study has some limitations that need to be considered. Measurement of MRR was performed during a maximal static respiratory maneuver. MRR has been shown to be effort dependent, and MRR becomes progressively faster at higher pressures as fast twitch type-II muscle fibers are progressively activated. ${ }^{26}$ Furthermore, maximal effort is more likely to recruit abdominal, upper airway, and neck muscles, resulting this way in a faster MRR, which does not necessarily reflect inspiratory muscle function. ${ }^{30} \mathrm{On}$ the other hand, and given these limitations, MRR has been applied as a measure to assess respiratory muscle fatigue both after a maximal effort ${ }^{12,25}$ as well as against an occluded airway. ${ }^{25,27}$ Another limitation of the study might be that the investigated CF subjects suffered as a whole relatively mild airway disease, as demonstrated by the aforementioned median pulmonary function indices, thus restricting the possibility to identify parameters associated with poor respiratory muscle function.

\section{Conclusions}

In conclusion, this study demonstrated that $\mathrm{CF}$ patients exhibit significantly increased MRR- $\mathrm{P}_{\text {Emax }}$ and significantly lower MRPD- $\mathrm{P}_{\text {Emax }}$ values, compared to the general population. MRPD was significantly related to BMI and UAMA, while MRR-P $\mathrm{P}_{\max }$ was significantly related to $\mathrm{FEV}_{1}, \mathrm{FVC}$, BMI, and UAMA, underlying the contribution of compromised nutrition and pulmonary function to impaired respiratory muscle function. The significant positive relation of MRPD to maximal respiratory pressures and of MRR-P $\mathrm{Imax}_{\text {max }}$ to $\mathrm{PTI}_{\text {mus }}$ might indicate a possible utility of these indices as accessory tools in the assessment of respiratory muscle function in CF patients. Application of measurement of MRPD and MRR in clinical practice might facilitate making decisions on initiation of treatment modalities such as noninvasive ventilation and inspiratory muscle training. 


\section{Maximum Rate of Pressure Development and Relaxation Rate of Respiratory Muscles}

\section{REFERENCES}

1. Mier A, Redington A, Brophy C, Hodson M, Green M. Respiratory muscle function in cystic fibrosis. Thorax 1990;45(10):750-752.

2. Szeinberg A, England S, Mindorff C, Fraser IM, Levison H. Maximal inspiratory and expiratory pressures are reduced in hyperinflated, malnourished, young adult male patients with cystic fibrosis. Am Rev Respir Dis 1985;132(4):766-769.

3. Hahn A, Ankermann T, Claass A, Mann M, Lindemann H, Neubauer BA. Non-invasive tension time index in relation to severity of disease in children with cystic fibrosis. Pediatr Pulmonol 2008;43(10): 973-981.

4. Hayot M, Guillaumont S, Ramonatxo M, Voisin M, Prefaut C. Determinants of the tension-time index of inspiratory muscles in children with cystic fibrosis. Pediatr Pulmonol 1997;23(5):336-343.

5. Cropp GJ, Pullano TP, Cerny FJ, Nathanson IT. Exercise tolerance and cardiorespiratory adjustments at peak work capacity in cystic fibrosis. Am Rev Respir Dis 1982;126(2):211-216.

6. Marks J, Pasterkamp H, Tal A, Leahy F. Relationship between respiratory muscle strength, nutritional status, and lung volume in cystic fibrosis and asthma. Am Rev Respir Dis 1986;133(3):414-417.

7. Lands LC, Heigenhauser GJ, Jones NL. Respiratory and peripheral muscle function in cystic fibrosis. Am Rev Respir Dis 1993;147(4): 865-869.

8. Goldfarb CA, Panitch HB. Chronic respiratory failure and the roles of noninvasive ventilation and lung transplantation. In: Allen JL, Panitch HB, Rubenstein RC, editors. Cystic fibrosis. New York: Informa Healthcare; 2010;372-389.

9. Tzelepis GE, Kasas V, McCool FD. Inspiratory muscle adaptations following pressure or flow training in humans. Eur J Appl Physiol Occup Physiol 1999;79(6):467-471.

10. Romer LM, McConnell AK. Specificity and reversibility of inspiratory muscle training. Med Sci Sports Exerc 2003;35(2):237-244.

11. ATS/ERS Statement on respiratory muscle testing. Am J Respir Crit Care Med 2002;166(4):518-624.

12. Kyroussis D, Mills G, Hamnegard CH, Wragg S, Road J, Green M, et al. Inspiratory muscle relaxation rate assessed from sniff nasal pressure. Thorax 1994;49(11):1127-1133.

13. Fauroux B. Why, when and how to propose noninvasive ventilation in cystic fibrosis? Minerva Anestesiol 2011;77(11):1108-1114.

14. O'Sullivan. Cystic fibrosis: diagnosis, sweat testing, and newborn screening. In: Allen JL, Panitch HB, Rubenstein RC, editors. Cystic fibrosis. New York: Informa Healthcare; 2010:90-102.

15. Black LF, Hyatt RE. Maximal respiratory pressures: normal values and relationship to age and sex. Am Rev Respir Dis 1969;99(5): 696-702.

16. Gaultier C, Boule M, Tournier G, Girard F. Inspiratory force reserve of the respiratory muscles in children with chronic obstructive pulmonary disease. Am Rev Respir Dis 1985;131(6):811-815.
17. Ramonatxo M, Boulard P, Prefaut C. Validation of a noninvasive tension-time index of inspiratory muscles. J Appl Physiol 1995; 78(2):646-653

18. Quanjer PH, Tammeling GJ, Cotes JE, Pedersen OF, Peslin R, Yernault JC. Lung volumes and forced ventilatory flows. Report Working Party Standardization of Lung Function Tests, European Community for Steel and Coal. Official Statement of the European Respiratory Society. Eur Respir J Suppl 1993;16:5-40.

19. Hankinson JL, Odencrantz JR, Fedan KB. Spirometric reference values from a sample of the general US population. Am J Respir Crit Care Med 1999;159(1):179-187.

20. Stallings VA, Stark LJ, Robinson KA, Feranchak AP, Quinton H. Evidence-based practice recommendations for nutrition-related management of children and adults with cystic fibrosis and pancreatic insufficiency: results of a systematic review. J Am Diet Assoc 2008; 108(5):832-839.

21. Kuczmarski RJ, Ogden CL, Guo SS, Grummer-Strawn LM, Flegal KM, Mei Z, et al. CDC growth charts for the United States: methods and development. Vital Health Stat 2000;2002(246):1-190.

22. Ramsey BW, Farrell PM, Pencharz P. Nutritional assessment and management in cystic fibrosis: a consensus report. The Consensus Committee. Am J Clin Nutr 1992;55(1):108-116.

23. Frisancho AR. New norms of upper limb fat and muscle areas for assessment of nutritional status. Am J Clin Nutr 1981;34(11):25402545.

24. Romer LM, McConnell AK, Jones DA. Effects of inspiratory muscle training on time-trial performance in trained cyclists. J Sports Sci 2002;20(7):547-562.

25. Esau SA, Bye PT, Pardy RL. Changes in rate of relaxation of sniffs with diaphragmatic fatigue in humans. J Appl Physiol 1983;55(3): 731-735.

26. Mulvey DA, Koulouris NG, Elliott MW, Moxham J, Green M. Maximal relaxation rate of inspiratory muscle can be effort-dependent and reflect the activation of fast-twitch fibers. Am Rev Respir Dis 1991;144(4):803-806.

27. Mador MJ, Kufel TJ. Effect of inspiratory muscle fatigue on inspiratory muscle relaxation rates in healthy subjects. Chest 1992;102(6): 1767-1773.

28. Hart N, Polkey MI, Clement A, Boule M, Moxham J, Lofaso F, et al. Changes in pulmonary mechanics with increasing disease severity in children and young adults with cystic fibrosis. Am J Respir Crit Care Med 2002;166(1):61-66.

29. Barry SC, Gallagher CG. Corticosteroids and skeletal muscle function in cystic fibrosis. J Appl Physiol 2003;95(4):1379-1384.

30. Kyroussis D, Johnson LC, Hamnegard CH, Polkey MI, Moxham $\mathrm{J}$. Inspiratory muscle maximum relaxation rate measured from submaximal sniff nasal pressure in patients with severe COPD. Thorax 2002;57(3):254-257. 